evolutionary processes, but is now recognised as a valuable factory for compounds with potential medical value for mankind.

Enchanting though the biological and behavioural descriptions are, the sections on cladistics (a study of relationships using nested sets of characters to produce a systematic classification), nomenclature and identification are the essential utilitarian core of the book. The catalogue will remain a primary reference source for many years, and yet, by including under each species paragraphs on distribution, mimicry, larval foodplants and adult attractants, some of which are incomplete, the reader is implicitly given an opportunity to contribute more data. The identification keys are clearly laid out and supported by 120 pages of figures and plates, some in colour, including eggs, larvae, pupae, adults and dissected genitalia.

Perhaps of most interest to Oryx readers is the section on faunistics, in which a careful consideration of conservation has been included. Based on the detailed review of distribution, it has been calculated that the conservation of the danaines of just 31 selected territories would ensure the survival of representative populations of all 157 species. Most of these 31 'critical faunas' are located in islands of the Indo-Pacific region, including 11 Indonesian islands, several parts of the Philippines, Papua New Guinea and other islands in Malesia and the south-west Pacific. Islands in the Indian Ocean and the Caribbean, together with a handful of mainland continental countries, make up the remainder. Whilst the authors stress that the omission of countries from the list is no excuse for disregarding local conservation needs, the 'critical faunas' indicate centres of diversity and give valuable guidance in the disbursement of limited international conservation resources.

In the recent years of economic recession, taxonomy in Britain has been reduced, and staff and subject matter have been under careful scrutiny. Insects are so diverse and entomologists so few that decisions on priorities have had to be taken. Basic, or curiosity-driven, research is often the first to go, allowing strategic, or applicationsdriven, research to continue. But the definition of strategic (or applied) research is not always simple 184 and requires careful consideration. Conservation, with its history of rear-guard actions and highly charged debate, has not always been given serious consideration as an applied subject, particularly in entomology. Yet it is quickly coming of age as a scientific discipline. Recognition of the role of conservation in its partnership with development, in the sustainable exploitation of nature and in its many hidden benefits to mankind, has brought conservation studies to the fore. Milkweed butterflies are not serious pests, nor do they have any value in biological control, but they have attracted long-term systematic study because of their highly complex array of biological interactions with other animals and plants. They have the potential to be used as sensitive indicators of perturbations to their environment, and this book on their systematics and biology gives the baseline data needed to develop this. The analysis of critical faunas provides important new criteria for locating such conservation applications. Milkweed Butterflies is of a quality and pattern that will set new standards in entomological systematics for many years to come.

Mark Collins, IUCN Conservation Monitoring Centre, Cambridge

\section{Frogs and Toads}

Trevor Beebee

Whittet Books, 1985, $£ 4.95$

Frogs and toads follow robins and hedgehogs in the newest publication of the Whittet series on wild animals in Britain. Numerous delightful illustrations by Guy Troughton, and an informal but informative text, provide the perfect balance for those with only the occasional childhood memory of 'pond dipping', as well as those with a serious

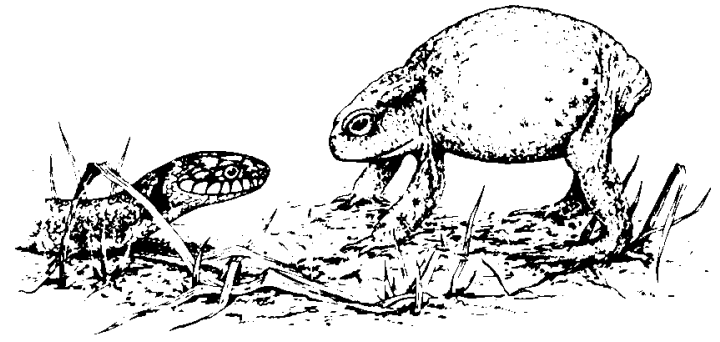

Defence position of toad when confronted by a grass snake (illustration by Guy Troughton, from Frogs and Toads by Trevor Beebee). 
interest in natural history-or even an academic approach! The entertaining and lucid text is divided into 30 short chapters covering biology, ecology, behaviour and conservation aspects of the anuran world. This is a book that will guide and inform the beginner, and charm those who appreciate such a readable style of natural history.

Tom Langton, FFPS staff herpetologist

\section{IUCN Commission on Ecology Publications}

Further details available from IUCN, Ave du Mont Blanc, CH-1196, Switzerland.

\section{Why Conservation?}

Commission on Ecology, Occasional Paper Number 4, IUCN, 1984.

This collection of questions-for example, 'If national parks are important as genetic storehouses, what is in it for the local people?' and 'How do you justify the total protection of certain species of plants and animals while actively encouraging the regular use of others?'-came from a letter sent to HRH The Prince of the Netherlands, Founder President of the WWF, by Professor Emil Salim, Minister of State for Development Supervision and the Environment in Indonesia. The answers given in this brochure are designed primarily for community leaders in developing countries, but have general applications.

\section{Future Hazards from Pesticide Use}

Dr F. Balk and Professor Dr J.H. Koeman

Commission on Ecology, Paper Number 6, IUCN, 1984

This study considers in careful detail two areas of the world (West Africa and South-巴\%st Asia) which are, like many other developing areas, increasing their use of pesticides and, thus, the risks to the environment. It describes how the hazards of pesticide use depend on type, dose rate, use pattern and local circumstances such as the condition of soils and water, climate, presence of endangered species and ecosystem structure. It describes how risk assessments should be made, and emphasises that these should be carried out on a regional basis rather than by extrapolation from one location to another, for example from a Book reviews temperate to a tropical zone. The main objective of the report is to guide authorities, companies and individual users of pesticides in selecting control methods that are appropriate from a pest management point of view, but at the same time compatible with nature conservation interests.

\section{Population and Natural Resources and other reports}

Commission on Ecology, Occasional Paper Number 3, IUCN, 1984.

The main report in this paper records the statement on Population and Natural Resources approved in November 1983 by the Council of IUCN and the Members' Assembly of the International Planned Parenthood Federation (IPPF). It also includes reports on various other meetings/ workshops of the IUCN Commission on Ecology in 1983 .

\section{Traditional Life-Styles, Conservation and Rural Development}

Proceedings of a Symposium organised by the Institute of Ecology, of Padjadjaran University, Bandung, and the IUCN Commission on Ecology held in Bandung, Indonesia, 4-5 October 1982. Edited by J. Hanks.

Commission on Ecology, Paper Number 7, IUCN, 1984

This consists of a multitude of papers on a wide range of traditional life-styles, which planning agencies cannot afford to overlook and, instead, should build upon in their attempts to smooth the transition of people who face change in their lives.

\section{Conservation of Ecological Processes} Professor R.E. Ricklefs, Professor Z. Naveh and Dr R.E. Turner

Commission on Ecology, Paper Number 8, IUCN, 1984

This 16-page essay urges us to take one more step forward in our approach to conservation. We have already advanced from the concept of species preservation to habitat conservation, and now it is time, the authors argue, to recognise that it is vital to conserve ecological processes. We should ensure that any ecosystem management works within the framework of natural patterns and cycles, leaving the maximum number of natural regulatory mechanisms intact. 